Dr. Harapandi Dahri, M.Ag., dkk.

\section{Untaian Mutiara \\ Dalam Khasanah Naskah Nusantara \\ Studi Filologi}




\section{KATA PENGANTAR}

Kepala Balai Penelitian dan Pengembangan Agama Jakarta

Naskah tulisan tangan (manuscript) merupakan salah satu bentuk khasanah budaya, yang mengandung teks tertulis mengenai berbagai pemikiran, pengetahuan, adat istiadat, serta perilaku masyarakat masa lalu. Dibandingkan dengan peninggalan budaya material non-tulisan di Indonesia, seperti candi, istana, masjid, dan lain-lain, jumlah peninggalan budaya dalam bentuk naskah jelas jauh lebih besar (Ikram 1997: 24). Naskah -yang sejauh ini masih sering diabaikan keberadaannya, dan hanya mendapatkan perhatian dari kelompok orang tertentu saja, khususnya para filolog dan pustakawan- sesungguhnya menyimpan makna dan dimensi yang sangat luas karena merupakan produk dari sebuah tradisi panjang yang melibatkan berbagai sikap budaya masyarakat dalam periode tertentu (Baried 1994:2).

Tradisi penulisan naskah pada masa lalu, di wilayah Indonesia khususnya, dan di Nusantara pada umumnya, tampaknya pernah terjadi dalam rentang waktu yang relatif panjang. Hal ini jika mempertimbangkan jumlah naskah Nusantara tersebut yang luar biasa banyak, tidak terbatas pada bidang kesusastraan saja, tetapi juga mencakup bidang lain seperti filsafat, adat istiadat, sejarah, hukum, obat-obatan, teknik, agama, dan lain-lain. Naskahnaskah tersebut sebagian telah tersimpan di perpustakaan, baik di dalam maupun di luar negeri, dan sebagian lagi masih "tercecer" di tanganmasyarakat. 
Seiring berjalannya waktu, dan dengan semakin luasnya cakupan wilayah islamisasi, distribusi naskah-naskah keagamaan tersebut pun semakin luas. Pada gilirannya, ketika naskah-naskah tersebut dibaca, dipahami, dan diresepsi kandungan isinya oleh masyarakat di berbagai daerah, maka muncul pula berbagai bentuk apresiasi dan resepsi dari masyarakat pembacanya, yang kemudian dituangkan juga dalam bentuk penulisan naskah.

Naskah-naskah tulisan tangan (manuscript) baik yang sudah tersimpansecara aman-di tempat-tempat penyimpangan naskah seperti Perpustakaan Nasional Republik Indonesia (PNRI) dan museum-museum sangat besar jumlahnya, ini menunjukkan kekayaan khasanah budaya dan agama yang merupakan warisan yang sangat berharga. Namun demikian, warisan yang amat berharga ini akan menjadi arsip lapuk bila tidak mendapat perhatian serius.

Sepanjang pengetahuan kami, kajian secara mendalam terhadap naskahnaskah klasik tersebut belum banyak mendapatkan perhatian dari parailmuan, baik dalam maupun luar negeri. Dengan demikian, kajian yang mendalam mendesak untuk dilakukan, agar naskah-naskah tersebut tidak hanya menjadi barang pajangan dalam museum atau dalam perpustakaan. Departemen Agama melalui Badan Litbang dan Diklat khususnya Puslitbang Lektur Keagamaan dan juga Balai Penelitian dan Pengembangan Agama Jakarta telah mulai serius menggarapnya dan hasilnya telah terkonservasi ratusan naskah klasik. Namun pekerjaan berat yang masih tersisa adalah melakukan kajian secara spesifik terhadap naskah-naskah yang telah dikonservasi dan dikumpulkan perlu dilakukan karena dengan kajian inilah naskah akan bermakna dan dapat dikonsumsi oleh publik dalam rangka menambah wawasan keilmuan mereka.

Menyadari persoalan tersebut, maka Balai Litbang Agama Jakarta melalui bidang Lektur Keagamaan mencoba melakukan kajian-kajian naskah klasik keagamaan dan hasilnya berupa buku yang diberi judul "Untaian Mutiara Dalam Khasanah Nusantara" seperti yang ada di tangan pembaca. Sangat disadari bahwa hasil kajian ini masih perlu perbaikan-perbaikan oleh karena itulah kami berharap masukan-masukan konstruktif agar hasil kajian-kajian 


\section{Bagian Kelima}

Jambi, H. Ahmad Kholid Dawam, Lc., M.Hum

Kajian Naskah Klasik Keagamaan: Studi Filologis Naskah Tasawuf Syaikh Muhammad Arsyad al-Banjari Koleksi Museum Negeri Jambi

Pendahuluan

Tinjauan Naskah Tasawuf Syeikh al-Banjari

Edisi Naskah Tasawuf Syeikh al-Banjari

Pembahasan Isi Naskah

Penutup 296

Daftar Pustaka 301

\section{Bagian Keenam}

Palembang, Zulkarnain Yani, S.Ag

Pesan Moral dalam Naskah Khutbah 'Idul Adha

Pendahuluan

Deskripsi Naskah

Edisi Teks Khutbah Idul Adha 309

Palembang dan Kebudayaan

Pesan Moral Naskah Khutbah 'Idul Adha

Penutup

Daftar Pustaka

\section{Bagian Ketujuh}

Bangka Belitung, Dr. Syahrul A'dam

Kajian Naskah Klasik Keagamaan: Studi Filologis yang Mengenal Dirinya Pasti Mengenal Tuhannya: Kajian Naskah Tentang Nur Muhammad

Pendahuluan

Inventarisasi dan Deskripsi Naskah

Suntingan Naskah tentang Nur Muhammad 353

Pokok-Pokok Pikiran Naskah tentang Nur Muhammad 359

Penutup 376

Daftar Pustaka 378 


\title{
Pesan Moral dalam Naskah Khutbah 'Idul Adha
}

\author{
Zulkarnain Yani, S.Ag
}

\section{Pendahuluan}

Salah satu tamaddun (peradaban) Islam di Indonesia adalah khasanah naskah-naskah klasik. Sejak abad-abad awal hijrah, Islam telah tumbuh sebagai agama yang dianut sebagian besar bangsa Indonesia. Perkembangan ini semakin pesat di abad $16 \mathrm{M}$, dimana Islam telah menyebar secara merata ke seluruh wilayah Nusantara. Salah satu kontribusi Islam di Nusantara ialah khasanah budaya, khususnya dalam bentuk naskah-naskah hasil karya para cendekiawan Muslim yang dituangkan dalam berbagai bentuk. Naskah-naskah tersebut berisiilmu-ilmu keagamaan, ilmu pengetahuan sosial dan pengetahuan umum (Hasan Muarif Ambary, 1998: 217).

Naskah klasik keagamaan Nusantara merupakan khazanah intelektual dan warisan berharga bangsa Indonesia. Oleh karena itu, upaya pelestarian, konservasi dan penggalian materi dan nilai-nilai yang terkandung di dalamnya merupakan sesuatu yang sangat diperlukan (Fadhal (ed), 2006: xiii). Sampai saat ini pemeliharaan warisan sejarah Nusantara, khususnya naskah-naskah keislaman, masih lebih diarahkan pada perawatan fisik, sehingga tidak banyak diketahui konsep-konsep dan corak pemikiran yang hidup dan berkembang pada masa lalu. Usaha-usaha pengumpulan naskah memang sudah lama dilakukan oleh perpustakaan dan museum dengan maksud yang baik untuk 
Palembang, wilayah penelitian kali ini, memiliki warisan kebesaran masa lampau yang sebagian telah dilestarikan dalam bentuk naskah dan kini aman tersimpan dalam perpustakaan di Indonesia dan Belanda. Dalam perpustakaan Universitas Leiden terdapat kumpulan naskah Sultan Badaruddin berjumlah 65 manuskrip yang ditempatkan di sana setelah kekalahan Palembang oleh Belanda. Perpustakaan Nasional menyimpan kurang lebih 45 naskah dalam berbagai kondisi. Sebagian besar naskah Palembang pada saat ini tersimpan dalam koleksi pribadi, hampir selalu merupakan bagian dari harta warisan yang diturunkan dari generasi-generasi sebelumnya. Pasang surutnya kehidupan para pemilik menyebabkan banyak kumpulan naskah berada dalam kondisi yang kurang baik. Peredaran zaman juga telah menyebabkan banyak naskah tidak dipakai atau dibaca lagi dan disimpat di tempat seadanya (Achadiati, 2004; 6).

Naskah-naskah kuno tersebut sebagian besar mengangkat tema-tema tasawuf, ilmu kalam, fiqih, akhlak, do'a, tafsir, hadis, mantra, cerita wayang, surat pribadi dan tulisan keagamaan yang lain. Naskah-naskah tersebut di antaranya menggunakan bahasa dan aksara Arab, bahasa Melayu aksara Arab, bahasa Arab aksara ulu, bahasa Melayu aksara Jawi, bahasa Melayu-Arab aksara Jawi, bahasa Arab-Melayu aksara Arab-Jawi, bahasa Melayu aksara Latin dan bahasa Palembang aksara Ka Ga Nga (Achadiati 2004; 4).

Salah satu naskah yang dikaji dalam penelitian ini adalah naskah Khutbah 'Idul Adha. Naskah ini merupakan koleksi pribadi Muhammad Jufri yang berasal dari Kakek Buyutnya yang bernama Mgs. Usman bin Mgs. Husin. Naskah Khutbah 'Idul Adha merupakan salah satu teks dari 3 teks yang terdapat dalam naskah tersebut yang kondisinya bisa dibaca. Isi dari Khutbah Idul Adhaitu sendiri berbicara tentang haji dan ibadah qurban yang dalam penelitian ini akan mengkaji tentang pesan-pesan moral yang ingin disampaikan oleh penulis.

Karena itu, secara khusus, penelitian ini bertujuan untuk; (1) menyajikan deskripsi teks Khutbah 'Idul Adha secara filologis, (2) menyajikan suntingan teks tersebut beserta kritik teks agar mudah dibaca dan terjemahannya agar mudah dipahami, dan (3) mengungkap pesan-pesan moral yang bisa diambil dari isi naskah. 


\section{Edisi Teks Khutbah 'Idul Adha}

\section{Pertanggungjawaban Suntingan Teks}

1. Tujuan

Salah satu tujuan pokok edisi teks ini adalah menyajikan teks Khutbah 'Idul Adhayang bersih dari berbagai kesalahan agar dapat secara mudah dibaca dan dimanfaatkan oleh kalangan yang lebih luas. Oleh karenanya, dalam edisi teks ini, saya telah melakukan berbagai langkah untuk mendukung tercapainya tujuan tersebut.

\section{Pertanggungjawaban Suntingan Teks}

Teks Khutbah 'Idul Adha yang menjadi objek penelitian ini ditulis dengan menggunakan bahasa dan aksara Arab standar (فصحة) yang masih dibaca dan dipahami oleh semua kalangan teks Khutbah 'Idul Adha ini memiliki tanda baca.

Kegiatan suntingan ini meliputi pemberian pungtuasi, titik, koma, titik koma, tanda hubung dan pembagian paragraf, karena teks khutbah 'idul adha tidak menggunakan tanda-tanda yang dikenal dalam bahasa Indonesia tersebut. Berikut ini beberapa prinsip yang dijadikan landasan dalam proses penyuntingan:

a. Pembagian paragraf yang dibuat berdasarkan kesatuan ide serta penggunaan pungtuasi, dimaksudkan untuk memudahkan pemahaman isi teks.

b. Perbaikan teks meliputi penggantian, penambahan, dan penghapusan bacaan yang dianggap menyimpang. Bacaan pengganti diusahakan berasal dari teks pendukung, dan jika tidak dijumpai, maka bacaan langsung diperbaiki berdasarkan kesesuaian dengan kaidah-kaidah bahasa Arab, sedangkan bacaan teks standar yang diganti, diletakkan dalam aparat kritik. Sedangkan penghapusan bacaan dilakukan pada bagian yang benar-benar dianggap sebagai bacaan menyimpang dan diperkuat oleh teks pendukung, atau merupakan pengulangan. Bagian bacaan yang dihapus ini selanjutnya diletakkan dalam aparat kritik supaya tidak mengganggu kelängsungan teks utama.

c. Nomor di akhir sebuah kata, yang ditulis agak naik ke atas, menunjukkan adanya catatan dalam aparat kritik mengenai kata 
Suntingan Teks

\section{الخُطبة العيد الاضحى}

(6) اللّ اكبر ملبر الاموز • وخالق الظلم و النور. وجاعل هن في القبور.

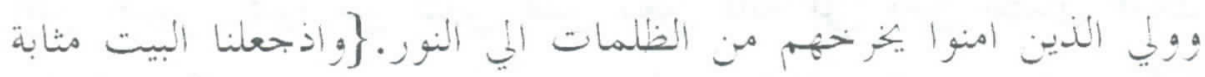

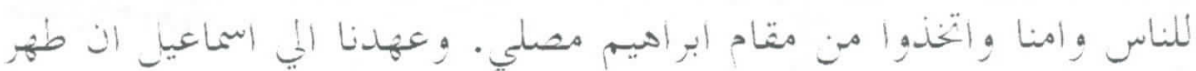
بيتي للطاثفين و العاكفين و الركع السجودج.

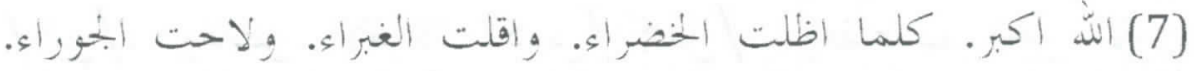

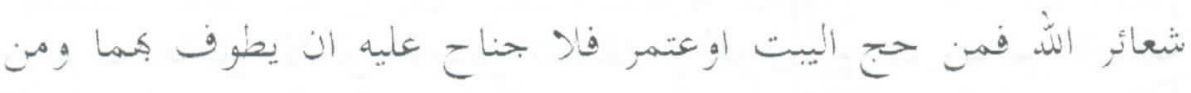

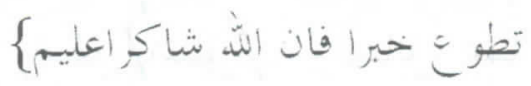

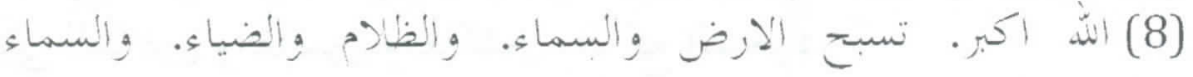

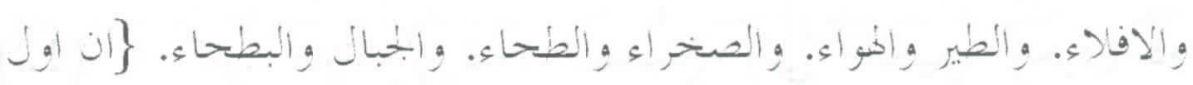
بيت وضع للناس للذي ببكة مباركا ومدى للعالمين. فيه ايات بيمنات

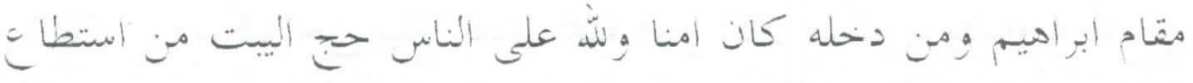

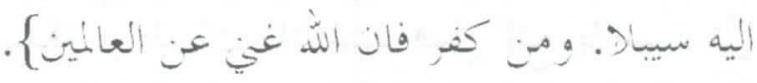

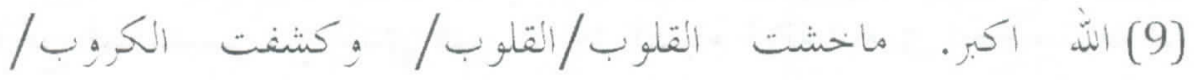

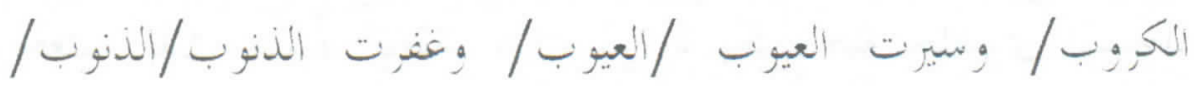

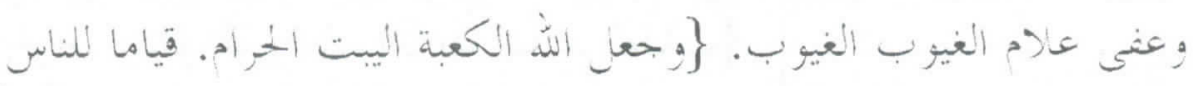

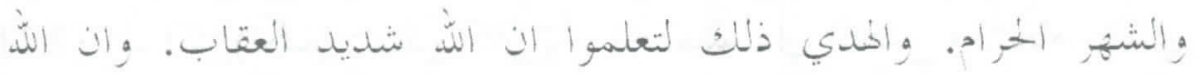


baik muslim. Kita memuji Allah atas kemuliaan 'id, kita bersyukur pada-Nya atas kemuliaan yang telah diberikan-Nya pada hari 'id. Aku bersaksi tidak Tuhan selain Allah tidak ada sekutu bagi-Nya, Ibrahim khalilullah diuji dalam kesaksiannya. Dia selamat (sukses) dari menyembelih anaknya.

Aku bersaksi bahwa Muhammad itu hamba dan rasul-Nya. Dia adalah Rasul yang diperintahkan untuk melaksanakan ibadah Jum'at dan 'iddi seluruh wilayah dan negara muslim. Shalawat dan salam kepada Muhammad dan keluarganya sebagaimana Dia juga bershalawat dan mengucapkan salam kepada Ibrahim khalilullah dan dia mengucapkan keselamatan yang banyak.

Wahai manusia, saya berwasiat kepada diriku dan kalian semua wahai hamba Allah untuk bertakwa kepada Allah. Kaum muslimin dan muslimat yang dirahmati Allah. Sesungguhnya Allah telah mendatangkan kepada kalian semua hari 'id, hari karamah dan keberuntungan sebagai tamu kalian dari Allah. Maka agungkanlah Ia seagung-agungnya, hari 'id adalah hari takbir

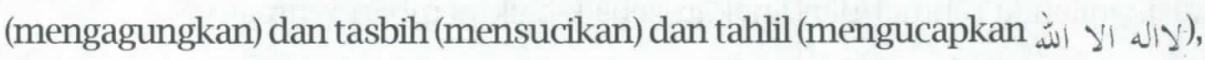
Ia merupakan muslim yang agung. Allah telah memuliakan hari 'id. Barang siapa berbuat baik pada hari itu maka kebaikannya akan diterima. Allah pada hari itu memerintahkan Nabi Ibrahim menyembelih Ismail dan Allah memberi petunjuk padanya dengan sebaik-baik ta'wil. Maka itu Ismail selamat lalu Allah memberikan Ibrahim seekor hewan qurban yang besar.

Laksanakanlah qurban wahai umat Islam pada hari-hari ini. Onta yang gemuk diqurbankan untuk 7 orang begitu juga sapi, seekor kambing untuk satu orang, maka bawalah qurban itu ketempat penyembelihan. Penyembelihan dilaksanakan setelah shalat, disunnatkan ketika penyembelihan menajamkan pisau, menghadap kiblat dan hendaklah orang yang menyembelih ketika menyembelih membaca بسم اللّ الدّ اكبر Ya Allah ini adalah qurban dari-Mu dan kembali kepada-Mu maka terimalah qurban dariku sebagaimana Engkau menerima qurban dari Ibrahim khalilullah dan Nabi Muhammad Saw. Dan berilah makan (qurban) orang yang qannah. Begitulah Allah memerintahkan kamu untuk berqurban agar kamu bersyukur. Rasulullah bersabda: Pilihlah qurbanmu yang gemuk, sesungguhnya ia menjadi tanggunganmu dalam perjalanan. Allah telah menjadikan kami dan kamu sekalian termasuk orangorang yang menang dan selamat. 
shalawat dan salam kami sampaikan kepada junjungan Nabi Muhammad Saw., keluargnya dan Nabi-Nabi-Mu yang diutus. Ya Allah, berikanlah ridhoMua kepada sahabat-sahabatnya, khalifah-khalifahnya Abu Bakar, Umar, Utsman dan Ali, Talhah dan Zubair, Sa'ad dan Sa'id, Abdurrahman bin 'Auf, Abi Ubaidah Amir bin al-Jarrah, mereka semua adalah pemimpin orang-orang yang beriman dan sebaik-baik manusia setelah Rasul.

Ya Allah, berikanlah ridha-Mu pada Hasan dan Husein, kedua pamannya yang mulia Hamzah dan Abbas, kepada istri-istrinya yang suci, ibu orangorang mukmin, kepada orang-orang muhajirin dan anshar, kepada para tabi'in dan tabi', bagi mereka kebaikan sampai hari kiamat, kami bersama mereka mudah-mudahan mendapatkan rahmat-Mu.

Ya Allah, ampunilah orang-orang muslim dan muslimat, orang mukmin dan mukminat baik yang masih hidup maupun yang sudah wafat. Sesungguhnya Engkau Maha dekat dan menjawab segala panggilan. Ya Allah jauhkanlah kami dari segala bala penyakit menular, kekejian, kemungkaran, kezaliman dan kekerasan yang beraneka ragam, penyiksaan dan segala ujian, baik yang tampak maupun yang tidak tampak dari negeri kami ini khususnya dan dari negeri orang-orang muslim secara umum. Sesungguhnya Engkau Maha Kuasa atas segala sesuatu. Ya Tuhan kami, berilah kami kebaikan di dunia dan di akhirat, lindungilah kami dari siksa api neraka.

Wahai hamba Allah, sesungguhnya Allah memerintahkan kamu sekalian untuk berbuat adil, berbuat kebaikan dan memberikan nafkah kepada kerabat dekat, Dia melarang kita kita dari perbuatan keji dan mungkar, kezaliman, Allah menasehati kalian agar kalian semua ingat. Lalu ingatlah kalian semua Allah yang Maha Agung, Dia akan mengingat kalian dan bersyukurlah atas nikmat yang telah diberikan-Nya, semoga Dia akan menambahkannya. Ingat Allah Tuhan yang Maha Agung.

\section{Palembang dan Kebudayaan}

\section{Arti Palembang dan Sejarah Kota Palembang}

Nama Palembang banyak mempunyai arti. Pengertian yang mendekati kenyataan adalah apa yang diterjemahkan oleh R.J.Wilkinson (1903) lembang adalah tanah yang berlekuk, tanah yang rendah, akar yang membengkak karena 
Batu-bersurat (prasasti) itu ditemukan oleh Controleur Batenberg di tepi sungai Kedukan Bukit, yakni diantara Bukit Seguntang dengan Situs Karanganyar pada tahun 1926 dengan menggunakan huruf Pallawa dan bahasa Melayu kuno. Prasasti tersebut oleh penduduk kampung Kedukan Bukit waktu itu dijadikan semacam tumbal bila akan mengikuti lomba Bidar, yakni dengan cara meletakkan di haluan Bidar yang akan diperlombakan. Konon, Bidar atau Perahu yang digentoli dengan batu "sakti-bertuah" itu senantiasa menang berlomba. Kemudian Batu-bersurat Kedukan Bukit itu ditelaah oleh para pakar sejarah dan kebudayaan, diantaranya Prof. M. Yamin yang menyatakan, itulah proklamasi (penggalian/pemindahan) ibukota Sriwijaya (dari tempat lain) ke Bukit Seguntang.

Prasasti Kedukan Bukit itu berbunyi sebagai berikut: (1) Swasti cri cakawarsatita 605 ekadaci cu (2) klapaksa wulan waicakha dapunta hiyang nayik di (3) samwau manalap siddhayatra disaptami cuklapaksa (4) wulan jyesta dapunta hiyang marlapas dari Minanga (5) Tamvan mamawa yam wala dualaksa danan koca (6) duaratus cara di samwau danan jalan sariwu (7) tluratus sapulu dua wannakna datam di Mukha Upang (8) Sukhacitta di pancami cuklapaksa wulan (9) laghu mudita datam marwuat wanua (10) Criwijava siddhayatra subhiksa. (Bacaan Prof. Poerbacaraka, G. Coedes, Prof. Dr. Ph.S. Van Ronkel Dr. Buchari, Prof. Slametmulyana).

Kota Palembang juga dipercayai oleh masyarakat Melayu sebagai tanah leluhurnya. Karena di kota inilah tempat turunnya cikal bakal raja Melayu pertama, yaitu Parameswara yang turun dari Bukit Siguntang. Kemudian Parameswa meninggalkan Palembang bersama Sang Nila Utama pergi ke Tumasik dan diberinyalah nama Singapura kepada Tumasik. Sewaktu pasukan Majapahit dari Jawa akan menyerang Singapura, Parameswara bersama pengikutnya pindah ke Malaka disemenanjung Malaysia dan mendirikan Kerajaan Malaka. Beberapa keturunannya juga membuka negeri baru di daerah Pattani dan Narathiwat (sekarang wilayah Thailand bagian selatan). Setelah terjadinya kontak dengan para pedagang dan orang-orang Gujarat dan Persia di Malaka, maka Parameswara masuk agama Islam dan mengganti namanya menjadi Sultan Iskandar Syah. 
menurunkan kekuasaan kepada raja-raja Melayu, yang mempunyai garis keturunannya. Kekuasaan ini berkembang di Malaka, yang pada gilirannya menurunkan raja-raja Melayu baik di Semenanjung Malaka, Sumatera dan kepulauan Riau.

Lembaran kedua catatan Palembang datang dari babad atau sejarah Jawa, termasuk Banten dan Cirebon. Babad yang paling mempengaruhi lembaran catatan Palembang adalah Babad Tanah Jawi. Lembaran ini mengetengahkan Aria Damar dan Raden Fatah. Kedua tokoh legendaris ini mengikat masa lampau Palembang dengan masa madyanya, antara Majapahit, Demak dan Palembang. Dari kedua tokoh ini kharisma Majapahit diturunkan melalui Demak kepada penguasa Palembang, dalam bentuk garis-garis silsilah penguasanya. Memantapkan silsilahnya, maka tokoh orang-orang suci seperti Walisongo dan para Nabi menjadi garis ke atas dari silsilah penguasa Palembang. Oleh karena itu, tidaklah heran garis-garis keturunan Palembang kaya sekali dengan pelbagai akar silsilah, di mana dapat kita baca pada saat perjalanan sejarah elit Melayu-Jawa memerintah di Palembang sejak paruh kedua abad ke-16.

Sebaliknya lembaran catatan daerah setempat, yaitu khususnya di daerah pedalaman Palembang, terdapat perkawinan antara yang berpuyang dengan Iskandar Zulkarnain, lewat Bukit Seguntang, dengan Majapahit, melalui Aria Damar. Muncul tokoh-tokoh yang namanya berbaur dan berciri Melayu-Jawa, di dalam akar silsilah mereka. Silsilah ini tertulis pada lontar, bambu atau secara tutur. Pengaruh budaya Melayu dan Jawa sampai sekarang pun masih bisa dibuktikan. Sebagai contohnya adalah bahasa, seperti pemakain kata "lawang (pintu)", “gedang (pisang)”, "jabo (luar)” dan masih banyak lagi. Gelar kebangsawanan pun bercorak demikian, seperti pemakaian gelar Raden Mas atau Raden Ayu. Makam-makam peninggalan masa Islam dan beberapa Masjid pun tidak berbeda bentuk dan coraknya dengan makam-makam Islam dan arsitek Masjid di Jawa. (triyono, 2007)

\section{Gerakan Tarekat di Palembang}

Di kalangan Alawiyin, tarekat tidak memiliki popularitas besar dan juga di Hadramaut, ekses-ekses ekstase organisasi religius ini dipandang dengan 
juga dibawa ke Sumatera dan Semenanjung Melayu oleh jemaah haji, yang di Mekkah dan Medinah berkenalan dengan tarekat baru ini. Juru dakwah pertama Sammaniyah, diantara anggota koloni Jawa di Mekkah ialah Abdusssamad alPalembani. Murid Syeikh Muhammad Samman ini di triwulan ketiga di abad ke-18 bermukim di Hijaz dan tetap aktif sebagai penulis sampai 1778 (Drewes, 1992: 74). Propagandis Sammaniyah yang lain ialah Kemas H. Ahmad yang juga berasal dari Palembang.

Melalui kedua tokoh ini, Sammaniyah kemudia bercabang ke Sumatera Selatan. Aneka silsilah Sammaniyah dari Palembang, sesudah Abdussamad al-Palembani menyebut nama Kiagus H. Muhammad Akib. Lahir sekitar 1760an di lingkungan mantri, Muhammad Akib bertolak ke Mekkah pada usia muda untuk studi lebih lanjut di Tanah Suci, dimana ia bergabung dengan Syeikh Abdussamad al-Palembani.

Sesudah kembali di Palembang, ia mulai menetap di kampung penghulon, di belakang Masjid Agung yang langsung berdekatan dengan keraton. Pemilihan tempat yang strategis ini sebenarnya amat menarik untuk disimak. Ada beberapa petunjuk mengenai hubungan erat antara Sultan Palembang dan tarekat ini. Pertama, dalam versi Palembang Hikayat Syeikh Muhammad Samad. Di dalamnya disebut sebuah zawiat yang didirikan Sultan Mahmud Baha'uddin sebagai wafatnya yang pada tahun 1776 , dengan menggunakan pemberian mulia 500 real.

Dalam pemilihan tempat ini dapat dilihat indikasi lalu lintas intelektual yang meningkat antara Palembang dan Timur Tengah. Mengingat Jeddah ialah pelabuhan terpenting untuk jemaah haji dalam perjalanan ke Mekkah, zawiyah ini sekaligus berfungsi sebagai penginapan jemaah haji dari Palembang dalam perjalanan mereka menuju kota suci. Kedua, hubungan antara keraton dan Sammaniyah dijumpai dalam bentuk naskah yang berasal dari Keraton Palembang. Dalam terjemahan bahasa Melayu Bahr al-Ajaib yang tersimpan dalam Perpustakaan Nasional, sebagai pengarang disebut Kemas Muhammad bin Kemas Ahmad, yang menulis manuskrip ini atas perintah Sultan Mahmud Badaruddin. Orang yang kita kenal sebagai penulis Hikayat Keramat Syeikh Muhammad Samman. Silsilah yang sampai sekarang masih disimpan di Palembang membenarkan hubungan antara kedua orang ini, yang selanjutnya 
Budayawan Sumatera Selatan Djohan Hanafiah menegaskan, para bangsawan Jawa yang berkeraton di Palembang pada akhirnya beradaptasi dengan budaya Melayu yang sudah tumbuh di daerah ini. Palembang juga merupakan kawasan kosmopolitan, dengan percampuran budaya berbagai bangsa yang datang seiring arus perdagangan.Artinya, sejarah ibu kota Provinsi Sumatera Selatan ini lebih panjang dari perjalanan sejarah Kota Baghdad di Irak yang didirikan tahun 762 , lebih tua dari Kyoto di Jepang yang didirikan tahun 794, apalagi dibandingkan dengan Jakarta yang berdiri tahun 1527.

Sejarah Kesultanan Palembang Darussalam yang jauh lebih muda dari masa Sriwijaya, meninggalkan jejak tak terputus dengan keberadaan Palembang masa kini. Namun, apresiasi masyarakat terhadap sejarah dan warisan budaya yang paling kasat mata dari masa kesultanan ini terkesan memprihatinkan. Naskah yang berasal dari masa Kesultanan Palembang Darussalam misalnya, antara lain ditemukan disimpan saja dalam rak di kamar mandi.

Substansi yang dipaparkan menyuguhkan wacana yang berkembang pada masa itu. Oleh karena itu, penemuan naskah berperan penting dalam kegiatan apresiasi kebudayaan dan kesejarahan. Penelitian awal yang digelar Yayasan Naskah Nusantara bekerjasama dengan Tokyo University of Foreign Studies di Palembang, Agustus lalu, menemukan bukti produktivitas sastra Melayu di daerah ini pada masa kesultanan.

Kegiatan penulisan mencapai puncaknya pada masa Sultan Mahmud Badaruddin (SMB) II yang diyakini Djohan sebagai pemimpin masa keemasan Kesultanan Palembang. Mujib Ali, peneliti pada kantor Asisten Deputi Urusan Arkeologi Departemen Kebudayaan dan Pariwisata yang pernah mendalami penulisan naskah kuno di Palembang, menuturkan, SMB II memang memiliki perpustakaan yang diduga terlengkap di Palembang masa itu. Puluhan naskah yang ditemukan Mujib memang ditandai sebagai milik SMB II.

Sayangnya, berbagai sumber sejarah menyebutkan, terjadi pembakaran tempat penyimpanan koleksi naskah pada saat kesultanan dijatuhkan Belanda tahun 1824. Sebagian naskah yang tersisa sempat dibawa oleh Belanda, sebagian lainnya justru dibakar oleh keluarga Sultan untuk menghindarkan pertentangan antarbangsawan. 
Kedukan Bukit (682 M). Prasasti yang ditemukan di tepi Sungai Tatang, sebelah barat Kota Palembang, pada tahun 1920, ini menandai berdirinya Kerajaan Sriwijaya.

Berbagai temuan sejarah Kerajaan Sriwijaya, termasuk arca dan stupika, menunjukkan bahwa Sriwijaya menjalin kerja sama serta berkomunikasi erat dengan para saudagar dan pemuka agama dari Cina, India, dan Arab. Hal ini membuktikan bahwa Sriwijaya merupakan kerajaan yang besar, berpengaruh, dan diperhitungkan.

Sriwijaya memiliki rentang wilayah kekuasaan yang luas, meliputi hampir seluruh Sumatera, Semenanjung Malaka, dan Jawa. Setelah keruntuhan Sriwijaya, pada abad ke-14, Palembang berada di bawah kekuasaan Kerajaan Majapahit.

Namun, kekuasaan Majapahit tidak mengakar di kawasan ini. Majapahit sendiri diguncang perang saudara, tak lama setelah berekspansi ke Pulau Sumatera. Palembang nyaris menjadi daerah tak bertuan, hingga kekuasaan baru dibangun Ki Gede Ing Suro bersama para pengikutnya.

Kelompok bangsawan ini menyingkir ke Palembang, setelah kalah dalam perseturuan Kesultanan Demak di Jawa Tengah. Kontinuitas kultural Jawa tertanam sebagai dasar legitimasi Keraton Palembang. Budayawan Palembang Djohan Hanafiah mencatat, keterkaitan politik ini berakhir setelah Sultan Abdurrahman (1659-1706) memproklamasikan Kesultanan Palembang Darussalam pada tahun 1675.

Jeroen Peeters (1997 : 10-11) memaparkan, di kalangan keraton, misalnya, para pembesar Palembang diwajibkan menggunakan bahasa Jawa krama (bahasa Jawa halus), terutama kalau mereka menghadapi sang raja. Juga dalam pergaulan politik, orang Palembang lebih menyukai bahasa resmi keraton ini, seperti terbukti dari banyaknya piagam yang diserahkan keraton Palembang kepada para kepala adat di pedalaman. Akan tetapi, pemakaian bahasa ini tidak tersebar luas di luar lingkungan Keraton Palembang.

Merujuk pada sejumlah naskah berbahasa Jawa yang tersimpan di Royal Asiatic Society, London, Peeters meyakini, naskah-naskah tersebut juga hanya beredar di lingkungan keraton. Beberapa koleksi naskah berbahasa Jawa ini 
Saman di Madinah. Sebagian karya Palembani ditulis ketika ia masih berada di negeri Arab.

Karya-karya Palembani antara lain Hikayat al-Salikin dan Sair al-Salikin yang merupakan terjemahan karya al-Ghazali. Di samping dua kitab berbahasa melayu tersebut, terdapat pula Zahrat al-Murid fi Bayan Kalimat al-Tauhid, dan lima kitab keagamaan lainnya yang berbahasa Arab.

Sebagian buku-buku al-Palembani merupakan naskah yang masih tersimpan di berbagai perpustakaan, antara lain di Perpustakaan Museum Nasional Jakarta, Perpustakaan Universitas Leiden, Belanda, dan Russian Institute of Oriental Studies di Leningrad, Rusia.

Mujib menyebutkan, naskah "favorit" Sultan Mahmud Badaruddin II yang ia temukan dalam penelitiannya adalah Mir'atu al-Tulabkarya Ar Raniri. Peneliti pada Kantor Asisten Deputi Urusan Arkeologi ini menjelaskan, kitab ini berisikan pedoman pelaksanaan tata pemerintahan kesultanan. (DAY).

\section{Pesan Moral Naskah Khutbah 'Idul Adha}

Secara umum dapat dikatakan bahwa bentuk penyampaian moral dalam sebuah karya mungkin bersifat langsung atau sebaliknya tidak langsung. Namun sebenarnya, pemilahan itu hanya demi praktisnya saja sebab mungkin saja ada pesan yang bersifat agak langsung.

1. Bentuk penyampaian langsung. Bentuk penyampaian pesan moral yang bersifat langsung, boleh dikatakan identik dengan cara pelukisan watak tokoh yang bersifat uraian, telling atau penjelasan. Artinya, moral yang ingin disampaikan atau diajarkan kepada pembaca itu dilakukan secara langsung dan eksplisit . Pengarang, dalam hal ini, tampak bersifat menggurui pembaca, secara langsung dalam memberikan nasihat atau petuahnya.

2. Bentuk penyampian tidak langsung. Bentuk penyampaian pesan moral bersifat tidak langsung. Pesan itu hanya tersirat dalam karya. Kalaupun ada yang ingin disampaikan, hal itu hanyalah lewat siratan saja dan terserah kepada penafsiran pembaca. Hubungan yang terjadi antara pengarang dan pembaca adalah hubungan tidak langsung dan tersirat. 
(Mekkah) dalam setiap melaksanakan shalat, akan terus memancarkan rahmat dan berkah-Nya atas kota itu. Selama kaum muslimin menghadapkan wajahnya ke kota Mekkah maka berkah itu akan terus memancar dan memberikan petunjuk bagi seluruh umat manusia di semesta ini.

\section{Pesan tentang Keutamaan Hari Idul Adha}

Pesan ketiga yang ingin disampaikan oleh penulis adalah tentang keutamaan hari 'id yang terdapat dalam kalimat berikut:

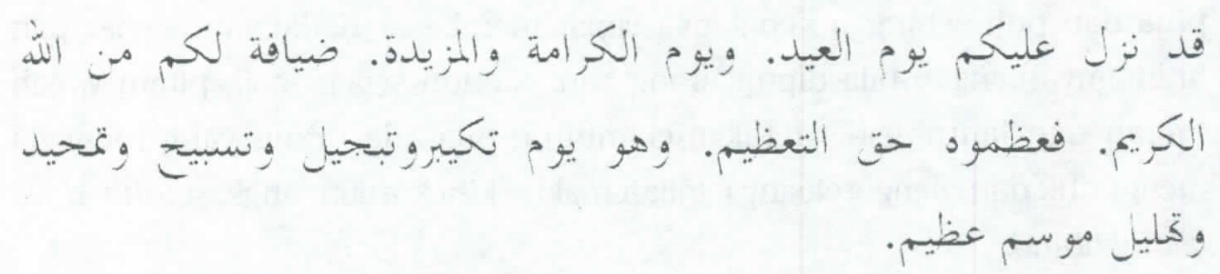

Artinya : Sesungguhnya Allah telah mendatangkan kepada kalian semua hari 'id, hari karamah dan keberuntungan sebagai tamu kalian dari Allah. Maka agungkanlah Ia seagung-agungnya, hari 'id adalah hari takbir (mengagungkan) dan tasbih (mensucikan) dan tahlil (mengucapkan

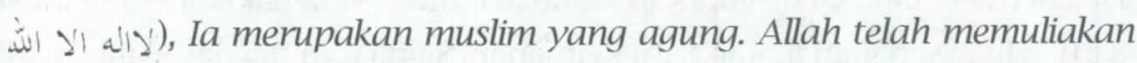
hari 'id. Barang siapa berbuat baik pada hari itu maka kebaikannya akan diterima.

$$
\begin{aligned}
& \text { الخمدلنّ ذي الفضل والانعام. الذي انزل العيد ضيافة للانام. و جعله شعائر }
\end{aligned}
$$

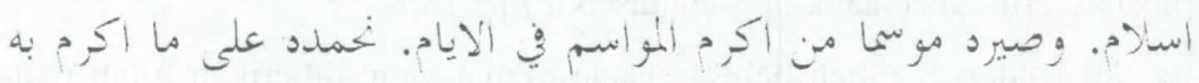

$$
\begin{aligned}
& \text { العيد. زونشكرة على ماشترفهم فيه وزالززيد. }
\end{aligned}
$$

Artinya : Segala puji bagi Allah yang memiliki segala kemuliaan dan nikmat, yang telah mendatangkan 'id sebagai tamu bagi manusia dan Allah menjadikan 'id itu bagian dari syiar Islam dan menjadikannya sebaikbaik muslim. Kita memuji Allah atas kemuliaan 'id, kita bersyukur padaNya atas kemuliaan yang telah diberikan-Nya pada hari 'id. 
tamak bahkan rakus tunggulah kekurangan kemiskinan dan kegelisahan hati selalu menghimpitnya.

Pesan tentang Pengorbanan

$$
\text { ابتلى فيه ابر اهيم خليله. وزتحى مـ الذبح ابنه سليله }
$$

Artinya: Ibrahim khalilullah diuji dalam kesaksiannya. Dia selamat (sukses) dari menyembelih anaknya.

Dalam kalimat di atas, penulis ingin menyampaikan tentang pengorbanan Nabi Ibrahim as yang diuji oleh Allah Swt. untuk menyembelih anak Ismail as. Sejarah membuktikan, bahwa pengorbanan senantiasa menduduki peran sentral sepanjang sejarah kehidupan umat manusia. Pengorbanan adalah idiom kehidupan yang tak pernah usang, dan ia tidak boleh mati. Bahkan ia harus senantiasa hidup dan dihidupkan setiap saat dan zaman oleh siapapun yang ingin meraih kemuliaan. Sebab jika umat tak lagi memiliki karakter ini, kehidupan akan mati dan jatuh pada kehinaan. Pengorbanan tak ubahnya ibarat ruh dalam kehidupan. Tanpa pengorbanan, dunia ini hanya akan dihuni oleh sosok-sosok manusia yang mati secara akidah, dan mati cita-citanya untuk meraih kemuliaan.

\section{Pesan tentang Kewajiban Ibadah Haji}

Pesan keempat yang disampaikan oleh penulis yaitu berkenaan dengan keutamaan:

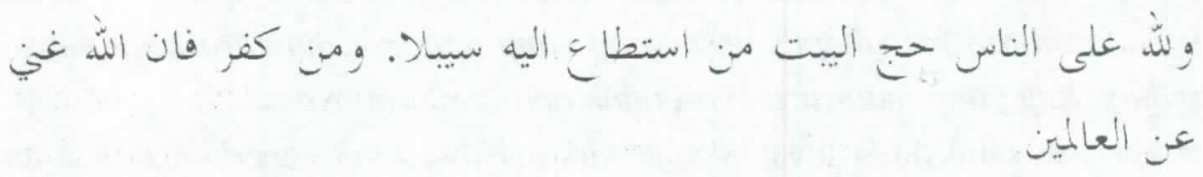

Artinya:Ibadah haji adalah sebuah kewajiban atas manusia yang memiliki kemampuan. Dan barang siapa mengingkarinya, sesungguhnya Allah maha kaya tidak butuh pada manusia.

Penulis menyampaikan bahwa ibadah haji adalah suatu kewajiban bagi semua umat Islam yang memiliki kemampuan. Allah mewajibkan haji ini 
Dalam Idul Adha kita diajarkan berqurban untuk orang lain dari apa yang kita miliki saat ini yang dapat dimanfaatkan oleh orang lain di sekitar kita. Jadi bukan hanya sekedar qurban kambing atau sapi setiap tahun melainkan kita diajarkan untuk selalu setiap saat siap berqurban untuk siapa saja yang membutuhkan pertolongan kita. Hal yang paling sederhana saja kita melihat ada seseorang yang sibuk dengan menginvestasikan uangnya untuk membeli rumah atau mobil padahal dia sudah memiliki semuanya lebih dari cukup, padahal masih banyak orang yang masih bingung mau tinggal dimana, atau besok mau makan apa. Alangkah lebih baik bilamana kita dapat membantu saudara kita yang masih belum punya rumah tinggal atau memberikan santunan kepada orang yang berhak menerimanya. Kadang kala kita hanya terpatok bahwa kita sudah mengeluarkan zakat 2,5\% padahal nilai itu tidak ada artinya dibandingkan harta yang dimiliki. Sebagai seorang hamba Allah yang baik maka kita pasti akan berpikir untuk membelanjakan harta kita yang diamanahi Allah pada kita untuk disalurkan kepada saudara-saudara kita yang membutuhkan tanpa terbatas dari 2,5\% tadi.

\section{Penutup}

\section{Kesimpulan}

Ada beberapa kesimpulan yang bisa diambil dari hasil penelitian ini, antara lain:

1. Naskah-naskah klasik keagamaan yang bernafaskan Islam yang terdapat di kota Palembang secara kuantitatif cukup banyak dan sebagian besar belum dilakukan penelitian ataupun kajian. Naskahnaskah tersebut sebagian besar mengangkat tema-tema tasawuf, sejarah kesultanan, tauhid, tafsir, fiqih, dan mengenai persoalan keagamaan masyarakat.

2. Naskah khutbah 'idul adha merupakan salah satu karya monumental yang ada di kota palembang, walaupun dari dalam naskah tersebut tidak menyebutkan siapa penulis naskah.

3. Pesan-pesan moral yang disampaikan dalam naskah tersebut mengenai ; a). Pesan tentang keagungan Baitullah, b.) Pesan tentang keutamaan hari raya 'Idul Adha, c.) Pesan tentang pengorbanan, d.) 
Pesan tentang kewajiban ibadah haji dan, e.) Pesan tentang keutamaan ibadah qurban.

4. Dari pesan-pesan moral tersebut bisa dijadikan pedoman bagi masyarakat dalam melaksanakan kehidupan keagamaan sehari-hari.

\section{Rekomendasi}

Dari penelitian ini, ada beberapa hal bisa direkomendasikan, antara lain:

1. Penelitian naskah-naskah klasik keagaman yang ada di kota Palembang agar terus dilakukan dengan harapan akan dapat menggali lebih dalam tentang pola kehidupan keagamaan yang ada di kota Palembang.

2. Kajian terhadap naskah Khutbah Idul Adha pun harus terus dilakukan dengan melakukan berbagai pendekatan, baik dari pendekatan teoriteori sastra maupun teori sejarah, antropologi, sosiologi dan lain sebagainya.

\section{Catatan Kaki:}

${ }^{1}$ Dalam hal ini, penulis tidak konsisten ketika menuliskan kalimat tersebut. 
Lubis, Nabilah., 2007, Naskah, Teks dan Metode Penelitian Filologi, (Jakarta; Yayasan Media Alo Indonesia.

Nurgiyantoro, Burhan., 1998, Teori Pengkajian Fiksi, Yogyakarta, Gadjah Mada University Press.

Tjadrasasmita, Uka., 2006, Kajian Naskah-Naskah Klasik dan Penerapannya bagi Kajian Sejarah Islam di Indonesia, Jakarta, Puslitbang Lektur Keagamaan Badan Litbang dan Diklat Departemen Agama.

Sayuti, Suminto A. 2001, Strukturalisme Dinamik dalam Pengkajian Sastra. www.suarakarya.com

Suwondo, Tirto. 2001, Analisis Struktural: Salah Satu Model Pendekatan dalam Penelitian Sastra. www.suarakarya.com 